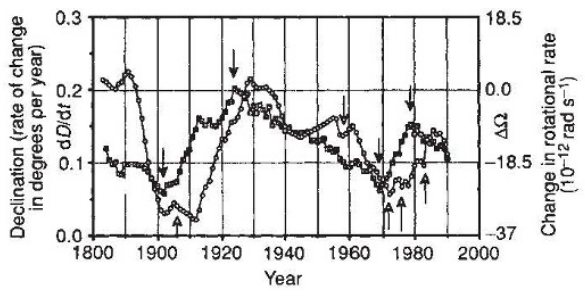

Changes in the Earth's rotation rate (circles, $\Delta \Omega$ ) in $10^{-12}$ rad $\mathrm{s}^{-1}$ (after ref. 9) are compared with secular variation of declination (squares, rate of change $\mathrm{d} D / \mathrm{d} t$ ) in degrees per year at the French national observatory (1883-1901, St Maur; 19021935, Val Joyeux; 1936-1990, Chambon-laForêt), considered as a representative indicator of geomagnetic secular variation. Open arrows, times of large Southern atmospheric oscillations; closed arrows, geomagnetic secular variation sharp changes of slope (around 1900, 1923, 1969 and 1978), otherwise called impulses or jerks. The fact that the time derivative of a single field component at a single observatory does provide a good indicator of worldwide secular variation (and in particular of jerks) has been discussed elsewhere, and illustrated by a number of harmonic coefficients of global expansions (see ref. 10). The normalized cross-covariance between the two curves reaches a clear, principal maximum of 0.74 for a time offset of $9 \pm 2$ years.

smaller than predicted by simple orderof-magnitude considerations. Small variations of the flow with respect to this configuration can, however, take place; if at some time a change in flow configuration suddenly occurs, this will be translated instantaneously into a change in the rate of secular variation (except for the delay introduced by the conducting mantle, which is probably of the order of a year). The torque exerted on the mantle will increase (from zero) and, when large enough will, with some delay, accelerate or decelerate the mantle.

\section{J. L. LE MOUËL V. COURTILLOT D. JAULT}

Institut de Physique du Globe,

Département de Géomagnétisme et Paléomagnétisme,

4 Place Jussieu,

75252 Paris Cedex 05, France

1. Le Mouëi, J. L., Madden, T. R., Ducruix, J. \& Courtillot, V. Nature, 290, 763-765 (1981).

2. Courtillot, V., Ducruix, J. \& Le Mouël. J. L. C.R. Acad Sci. Paris. Ser. D.287, 1095-1098 (1978)

3. Gire, C. \& Mouël, J. L. in The Earth's Rotation: Solved and Unsolved Problems (ed. Cazenave, A.) 241-258 (Reidel, Dordrecht), (1986)

4. Jault, D., Gire, C. \& Le Mouël, J. L. Nature 333,353356 (1988)

5. Jault, D. \& Le Mouël, J. L. J. geomagn. Geoelectr. 43 111-129 (1991)

6. Hide, R. Nature 222, 1055-1056 (1969).

7. Jault. D. \& Le Mouël, J. L. Geophys. J. Int. 101 233-241 (1990)

8. Hinderer, J., Legros, H., Jault, D. \& Le Mouël, J. L. Phys. Earth planet. Int. 59, 329-341 (1990).

9. Morrison, L. V. Geophys. J. R. astr. Soc. 58, $349-360$ (1978).

10. Langel, R. A. \& Estes, R. H. J. geophys. Res. 90 2495-2509 (1985).

\title{
Anion guests in heteropolyanions?
}

SIR - Müller ${ }^{1}$ and Day et al. ${ }^{2}$, stimulated by Mitchell's News and Views article on inorganic host-guest chemistry $^{3}$, cited heteropolyanions as examples in which both anions and cations could be guests (or 'hostages'). I can claim some familiarity ${ }^{4}$ with this remarkably versatile class of compounds, which is also of growing significance in other disciplines such as materials science, medicine and topology.

In my view the 'anion-centred' heteropolyanions like $\left[\mathrm{PMo}_{12} \mathrm{O}_{40}\right]^{3^{-}}$are not analogous to the novel polyvanadate clathrate species that are being explored by Müller et al. and which were discussed by Mitchell. The host cluster shells of the latter species are negatively charged (and encapsulate anions) and are constructed of $\mathrm{OV}^{\mathrm{IV}} \mathrm{O}_{4}$ or $\mathrm{OV}^{\mathrm{V}} \mathrm{O}_{4}$ square pyramids. Simple valence-sum considerations imply that there will be very little excess charge density available for conventional $\mathrm{V}$... $\mathrm{O}$ bonding in a direction trans to the terminal oxo groups, that is, towards the interior of the shell. Although cluster shells of $\mathrm{OMo}^{\mathrm{VI}} \mathrm{O}_{4}$ or $\mathrm{OW}^{\mathrm{V}} \mathrm{O}_{4}$ square pyramids are also implicit in the clathrate description of ions like $\left[\mathrm{PMo}_{12} \mathrm{O}_{40}\right]^{3^{-}}$and
$\left[\mathrm{PW}_{12} \mathrm{O}_{40}\right]^{3-}$, such shells are uncharged, and the higher valences of molybdenum or tungsten vis-à-vis vanadium result in stronger interactions with the oxygens of the internal oxoanion. This leads to the conventional descriptions of these structures in terms of $\mathrm{OMO}_{5}$ octahedra.

Furthermore, it is clear from the observed structural variety of polyvanadate shells that the encapsulated anions (which are not even restricted to oxoanions for these complexes) act as templates and control the organization, size and shape of the surrounding cluster shells. This feature stands in contrast to the archetypal heteropolyanion Keggin structure which can be generated in the absence of tetrahedral oxanion templates, for example, the metatungstate anion $\left[\mathrm{H}_{2} \mathrm{~W}_{12} \mathrm{O}_{40}\right]^{6^{-}}$.

Department of Chemistry,

Georgetown University,

Washington, DC 20057, USA

1. Müller, A. Nature 352, 115 (1991)

2. Day, V. W., Klemperer, W. G. \& Yaghi, O. M. Nature 352. 115-116 (1991)

3. Mitchell, P. C. H. Nature 348, 15-16 (1990).

4. Pope, M. T. Heteropoly and Isopoly Oxometalates (Springer, Berlin, 1983).

\section{No lubricants from fluorinated $\mathbf{C}_{60}$}

SIR - Ever since $\mathrm{C}_{60}$ was discovered ${ }^{1}$, there has been anticipation of the possible use of the fluorinated derivatives, and $\mathrm{C}_{60} \mathrm{~F}_{60}$ in particular, as lubricants. There are indications, however, that, unlike Teflon, this material might not be chemically stable: fluorination of $\mathrm{C}_{60}$ is very slow, and steric crowding is predicted to increase the $\mathrm{C}-\mathrm{C}$ bond length by about $0.05 \AA$ (ref. 2) and decrease the $\mathrm{C}-\mathrm{F}$ bond strength by $15 \%$ relative to that in $\mathrm{CF}_{4}$ (ref. 3). We have found that highly fluorinated $\mathrm{C}_{60}$ does indeed seem to be highly chemically reactive.

In a study of the fluorination of $\mathrm{C}_{60}$ to give a mixture of fluorinated derivatives $^{4}$, we ascribed a peak at -188.5 p.p.m. in the ${ }^{19} \mathrm{~F}$ NMR spectrum of the product to $\mathrm{HF}$, the origin of which was unclear. Moreover, the acetone solvent underwent rapid aldol condensation and darkening, consistent with the presence of HF. Handling the fluorinated material in air, however, seemed to present no great difficulties.

In further studies, we exposed $\mathrm{C}_{60}$ (contained in a Teflon tube rather than in glass as used previously) to fluorine gas for about six weeks. Acetone solutions of samples of the product discoloured immediately and the ${ }^{19} \mathrm{~F}$ NMR spectra showed a very substantial peak at $-190.5 \pm 1.5$ p.p.m.; this peak also appeared in a tetrahydrofuran (THF) solution, and its position and intensity varied with the amount of water present in the solvent. In confirming that this peak is due to $\mathrm{HF}$, we find that fluorinated $\mathrm{C}_{60}$ undergoes very rapid reaction with sodium carbonate to give sodium fluoride and a yellow water-soluble product, the colour intensity of which differs for acid and basic solutions (being deeper in the latter). We have monitored this reaction via disappearance of the broad band ${ }^{4}$ in the ${ }^{19} \mathrm{~F}$ NMR spectrum. This band decreased in intensity (at a decreasing rate) over $48 \mathrm{~h}$, and could then be further decreased by addition of sodium hydroxide. Fluorinated $\mathrm{C}_{60}$ undergoes nucleophilic substitution by hydroxide (confirmed by infrared studies), and the rate of this reaction decreases as the fluorine content of the fullerene becomes reduced.

The apparent stability of the material in air is presumably a consequence of its hydrophobic nature, which renders it relatively stable and insoluble. A sample suspended in water initially showed no visible signs of reaction, but on addition of a few drops of THF, an immediate and exothermic reaction took place, and NMR analysis showed that substantial quantities of HF were produced. The formation of $\mathrm{HF}$ in acetone or THF solutions is thus due to the presence of traces of water, which attacks the solu- 